\title{
DESTAQUES DO PROJETO DO ALTO-FORNO 2 DA VSB*
}

\author{
Victor Freire de Oliveira ${ }^{1}$ \\ André Cabral de Oliveira ${ }^{2}$ \\ Mário Fernando Gomes D’Almeida Cunha ${ }^{3}$ \\ Renato Van Doornik Dutra \\ Paulo César Lemes de Almeida ${ }^{5}$ \\ Aline Miranda Pessoa Passagli ${ }^{6}$ \\ Onidio Teixeira Pinto Junior ${ }^{7}$
}

\section{Resumo}

Em 24 de julho de 2014 entrou em operação o alto-forno 2 da VSB, projeto de fornecimento Paul Wurth cuja conclusão de montagem foi em 2011. O alto-forno, primeiro montado de um total de dois fornecidos, foi desenvolvido para conferir à VSB a maior flexibilidade operacional possível sendo capaz, inclusive, de operar com coque ou carvão vegetal, alternadamente. A instrumentação e automação são modernas e avançadas, oferecendo à VSB amplo controle sobre o processo. A presente contribuição técnica visa apresentar as características que tornam o altoforno 2 da VSB um reator especial e o mais moderno em sua categoria.

Palavras-chave: Alto-forno; Processo; Projeto; Operação.

\section{VSB BLAST FURNACE 2 PROJECT HIGHLIGHTS}

\begin{abstract}
The blow-in of VSB's blast furnace 2 was performed in the second semester of 2014. The blast furnace was a Paul Wurth turn-key supply whose erection services were concluded in 2011. The furnace was the first one to be erected out of a total of two supplies, and it was designed to grant VSB the highest possible operational flexibility, which includes the possibility of operating with charcoal or coke, alternately. The automation and instrumentation applied to the project are modern and advanced, granting VSB a wide control over the blast furnace process. The present paper aims at presenting what are the project highlights that make this blast furnace such a special reactor.
\end{abstract}

Keywords: Blast furnace; Process; Project; Operation.

1 Engenheiro Químico, Engenheiro de Projetos, Tecnologia/Processos, Paul Wurth do Brasil, Belo Horizonte, MG, Brasil

2 Analista de Sistemas, Coordenador, Marketing \& Vendas, Paul Wurth do Brasil, Belo Horizonte, MG, Brasil

3 Engenheiro Metalurgista, Consultor Técnico, Marketing \& Vendas, Jomafe, Belo Horizonte, MG, Brasil

4 Engenheiro Eletricista, Engenheiro de Projetos, Tecnologia/Elétrica, Paul Wurth do Brasil, Belo Horizonte, MG, Brasil

5 Engenheiro Metalurgista, Engenheiro do Controle de Processo do alto-forno, VSB, Jeceaba, MG, Brasil.

6 Engenheira de Produção, Coordenadora do Controle de Processo do alto-forno, VSB, Jeceaba, MG, Brasil.

7 Engenheiro Metalurgista, Gerente do alto-forno, VSB, Jeceaba, MG, Brasil. 


\section{INTRODUÇÃO}

A Vallourec-Sumitomo Tubos do Brasil é uma joint venture formada pelo grupo francês Vallourec e pelo japonês Nippon Steel \& Sumitomo Metal Corporation [NSSMC] cujo complexo siderúrgico está localizado no município de Jeceaba, a $100 \mathrm{~km}$ de Belo Horizonte, Minas Gerais. A fim de suprir a demanda de gusa para a produção de 1 milhão de toneladas anuais de aço bruto e 600.000 toneladas de tubos, a VSB optou pela construção de dois altos-fornos de $350 \mathrm{~m}^{3}$ de volume útil para uma produção diária nominal de 840 toneladas. O primeiro deles, o alto-forno 2 , entrou em operação em 24 de julho de 2014, enquanto a montagem do alto-forno 1 aguarda, estrategicamente, a melhora do ambiente do mercado siderúrgico mundial. Dentre os sistemas instalados na área de redução da VSB, há várias particularidades de projeto que conferem aos altos-fornos projetados um nível operacional bastante avançado em comparação a outros projetos de capacidade semelhante. O presente trabalho visa a apresentar algumas dessas particularidades e diferenciais.

\section{DESTAQUES DE PROJETO DO ALTO-FORNO 2 DA VSB}

A presente seção visa ao detalhamento, para cada plant unit, de quais os diferenciais de projeto da instalação da VSB.

\subsection{Alto-forno Próprio}

As principais características do perfil do alto-forno 2 da VSB são apresentadas na Tabela 1.

Tabela 1. Principais características do perfil do alto-forno 2 da VSB

\begin{tabular}{ccc}
\hline Parâmetro & Unidade & Valor \\
\hline Produção nominal & $\mathrm{t}$ & 840 \\
\hline Volume útil & $\mathrm{m}^{3}$ & 350 \\
\hline Volume total & $\mathrm{m}^{3}$ & 401 \\
\hline Volume do cadinho & $\mathrm{m}^{3}$ & 62,4 \\
\hline $\begin{array}{c}\text { Número de } \\
\text { ventaneiras }\end{array}$ & unidades & 14 \\
\hline $\begin{array}{c}\text { Número de furos de } \\
\text { corrida }\end{array}$ & unidade & 1 \\
\hline
\end{tabular}

Originalmente o projeto foi concebido para contemplar a possibilidade de uso de coque nos altos-fornos durante os primeiros quatro anos de operação da usina, devido à adequação de produção da unidade florestal da Vallourec à demanda dos reatores. A mudança de operação de um alto-forno entre tipos diferentes de redutores exige adaptações do perfil do mesmo a fim de otimizar a operação do forno. Salienta-se que a densidade do coque é pelo menos o dobro da do carvão vegetal, o que muda completamente o comportamento e as propriedades da coluna de carga do forno.

Essa particularidade é o que define o maior volume do "sump" do alto-forno da VSB, quando comparado a outros altos-fornos operando a carvão vegetal. A altura entre a soleira e o furo de corrida de $1.350 \mathrm{~mm}$ é suficiente para equilibrar o balanço de forças para uma operação a coque. Levou-se em conta a redução da velocidade de 
escoamento do gusa no cadinho, visando-se à redução do desgaste por erosão e corrosão.

O revestimento refratário do alto-forno foi desenvolvido visando-se a uma campanha longa e segura. Os refratários da cuba foram selecionados de modo a oferecer alta resistência à álcalis e ao ataque de $\mathrm{CO}$, além de terem ancoragens revestidas para evitar quebra de materiais monolíticos por expansão diferencial. Cita-se, também, o uso de suporte do revestimento e o desenvolvimento de formas especiais para evitar o "efeito dominó" de regiões de desgaste localizado.

$\mathrm{Na}$ área das ventaneiras e nas paredes do cadinho foram usados blocos de carbono microporoso com excelente resistência a erosão e corrosão além de elevada condutividade térmica. Material monolítico foi usado para compensar movimentações e acomodações do revestimento. A alta condutividade do carbono também contribui para a formação de uma camada de material solidificado no cadinho, que reduz o desgaste dos blocos. $\mathrm{O}$ projeto, realizado com modelagem de elementos finitos, permitiu a obtenção de um conceito com baixo stress termomecânico e baixa tensão no revestimento refratário.

A soleira é resfriada nos dois níveis inferiores por tubos sem costura em serpentina inseridos em blocos de grafite. Os demais níveis são combinações de blocos padrão e microporosos de carbono, garantindo boa condutividade térmica e resistência ao desgaste. Tal resfriamento certamente conferirá maior longevidade ao cadinho, quando comparado com outros fornos de mesmo tamanho.

Vale observar que o design do cadinho foi semelhante ao aplicado no alto-forno 2 da usina Barreiro da Vallourec, em Belo Horizonte, MG. Na época do início do projeto dos fornos da VSB (2008), a campanha do forno 2 já se estendia por 8 anos, sem falhas ou serviços de manutenção no cadinho.

\subsubsection{Instrumentação e controle do forno}

O nível de instrumentação do alto-forno da VSB é bastante avançado, sendo que se podem citar alguns de seus principais sistemas:

- 1 analisador contínuo de gás de topo;

- 2 sondas radiais de temperatura;

- 18 termopares de inserção ao longo de toda a cuba;

- 48 termopares para monitoramento da carga térmica do circuito fechado de refrigeração;

- 96 termopares no ventre, rampa, soleira, carcaça do cadinho e capela;

- 4 termopares no canal de gusa;

- loop de controle de pressão de topo com atuação pelo elemento anular do lavador de gás;

- controle automático de temperatura de sopro mediante diluição de ar frio por by-pass;

- 2 Sondas mecânicas de carga com transmissores e chaves de nível;

- controle completo dos regeneradores;

\subsubsection{Sistema de resfriamento do alto-forno}

Os equipamentos de resfriamento do forno se dividem em dois circuitos: aberto e fechado, conforme listado na Tabela 2. 
Tabela 2. Organização dos sistemas de refrigeração do alto-forno 2

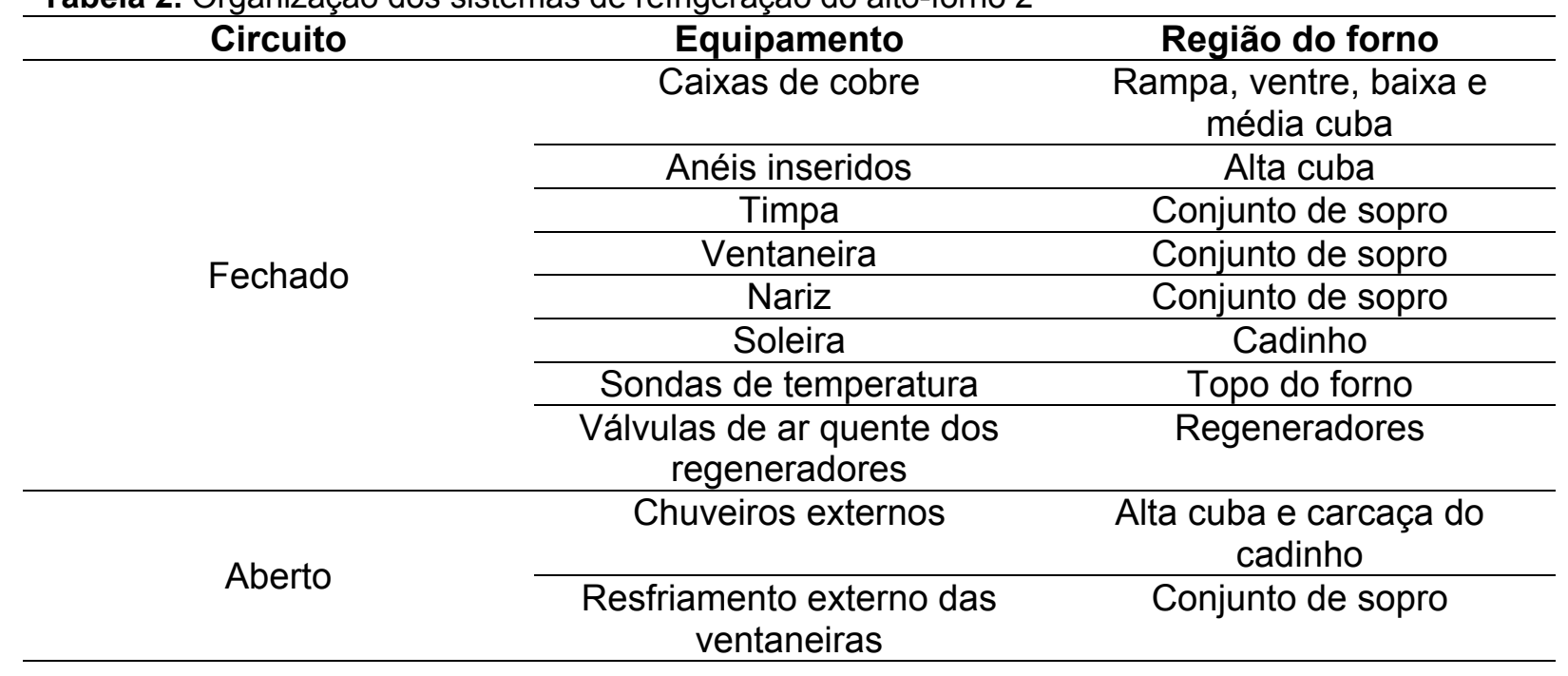

O circuito fechado tem a vantagem de manter a pressão da água constantemente superior a 3,0 bar(g), o que aumenta a temperatura de ebulição da água e evita a formação de bolhas de vapor que diminuiriam a eficiência de troca térmica do sistema. Adicionalmente, a ausência de contato com o ar externo reduz a aeração da água, melhorando as propriedades corrosivas do fluido. Tal característica, aliada ao pré-condicionamento da água de make-up de refrigeração em uma estação de tratamento confere ao sistema boa disponibilidade e baixa necessidade de manutenção. Deve-se citar também que pressão positiva evita a admissão de CO para a água de resfriamento em caso de vazamentos nos anéis de resfriamento ou caixas de cobre.

Adicionalmente, o circuito é equipado com um vaso pressurizado com nitrogênio com chaves de nível. Tal dispositivo permite a detecção de vazamentos no circuito. $\mathrm{Na}$ ocorrência de perda de nível no interior do tanque, uma válvula automática aumenta a vazão de reposição do sistema o que inclusive fornece uma idéia da dimensão do vazamento presente. A queda de pressão do vaso é compensada por uma válvula automática de nitrogênio. O fornecimento de nitrogênio ao vaso não só mantém a pressão do circuito constante, mas também evita a admissão de ar e aeração da água de resfriamento.

As placas de cobre utilizadas na baixa cuba e no ventre oferecem boa proteção ao revestimento refratário e, de acordo com experiências da Paul Wurth ao redor do mundo, podem ajudar a atingir campanhas superiores a 10 anos. A solução, aliada ao design do revestimento refratário, com anéis de suporte do revestimento refratário, oferece comprovadamente resultados melhores do que o uso de um revestimento mais espesso com apenas refrigeração externa da carcaça.

No geral, os sistemas de resfriamento estão preparados para garantir um tempo de campanha longo ao alto-forno da VSB.

\subsubsection{Conjuntos de sopro e sistema de troca rápida}

Os conjuntos de sopro utilizados na VSB são do tipo cardan da Paul Wurth, o que garante vedação adequada mesmo com pressões de sopro elevadas além de movimentos angulares ao redor de um centro geométrico, conforme demonstrado na Figura 1. 


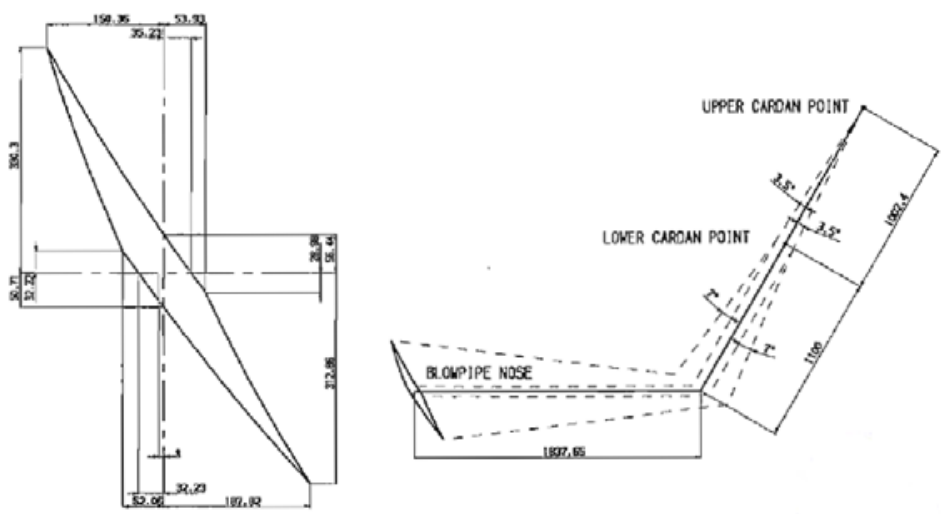

Figura 1. Diagrama de movimentação do conjunto de sopro cardan da Paul Wurth

Esse design permite uma distribuição adequada das cargas de pressão internas assim como a adaptação dos conjuntos de sopro à elongação da carcaça do forno e anel de vento.

Os conjuntos de sopro são revestidos com refratários monolíticos permitindo o uso de temperaturas de sopro elevadas e garantindo baixas perdas térmicas do sopro através do conjunto. As juntas articuladas possuem anéis de fibra cerâmica para vedação e proteção contra desgaste, aumentando a longevidade da montagem.

O projeto do sistema de troca dos conjuntos de sopro consiste em um pequeno "carrinho" para içamento do algaraviz, reduzindo drasticamente a necessidade de tempo e mão-de-obra para a retirada e reposição do mesmo no forno. $\mathrm{O}$ dispositivo é representado pela foto da Figura 2.

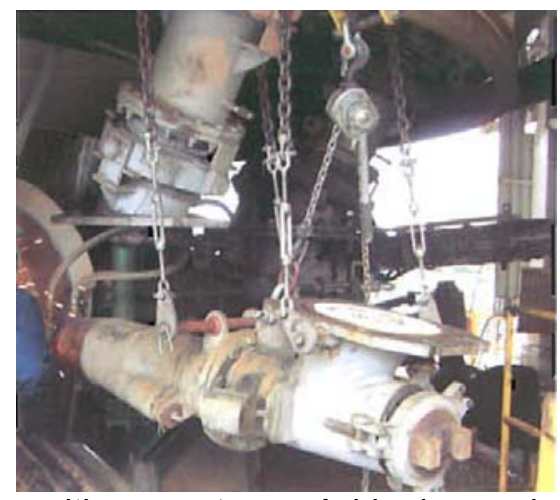

Figura 2. Dispositivo para troca rápida dos conjuntos de sopro

\subsection{Carregamento do aAto-forno}

No carregamento do forno destacam-se o sistema de secagem de minério e o SBPT (Single-Bell Pressurized Top). Além disso, destaca-se o design compacto da dosagem de ferrosos, cujo layout visa ao atendimento dos dois altos-fornos em uma construção única. Digno de observação é também o fato de que o desnível natural entre o piso zero do alto-forno e o piso zero da stockhouse, de $19 \mathrm{~m}$, foi aproveitado para o layout, possibilitando o uso de uma correia transportadora principal com apenas $12^{\circ}$ de inclinação e uma distância horizontal total da ordem de $135 \mathrm{~m}$.

\subsubsection{Sistema de secagem de minério}

O sistema foi desenvolvido para reduzir a umidade do minério de ferro de valores da ordem de $6 \%$ para $2 \%$. Tal redução oferece significativa economia de energia no 
alto-forno devido à redução do consumo energético para evaporação de umidade livre. Outro ganho é a melhora da eficiência de peneiramento do minério.

O gás de secagem utilizado é o gás queimado do aquecimento dos regeneradores, com uma temperatura de projeto da ordem de 100 a $280{ }^{\circ} \mathrm{C}$, podendo chegar até a $300-350{ }^{\circ} \mathrm{C}$. O gás, movimentado por um ventilador, permeia a carga de minério através de tubos perfurados e se distribui no interior do silo, dimensionado de acordo com a produção esperada do alto-forno.

O sistema, além de melhorar o condicionamento do minério, previsto para uso na ordem de $30 \%$ da carga ferrosa do forno, também representa reaproveitamento de energia, ganho de valor inquestionável em um tempo onde métodos sustentáveis de produção tornaram-se indispensáveis.

\subsubsection{Topo SBPT (Single-Bell Pressurized Top)}

O topo SBPT e o distribuidor de placas móveis são ilustrados pela na Figura 3.
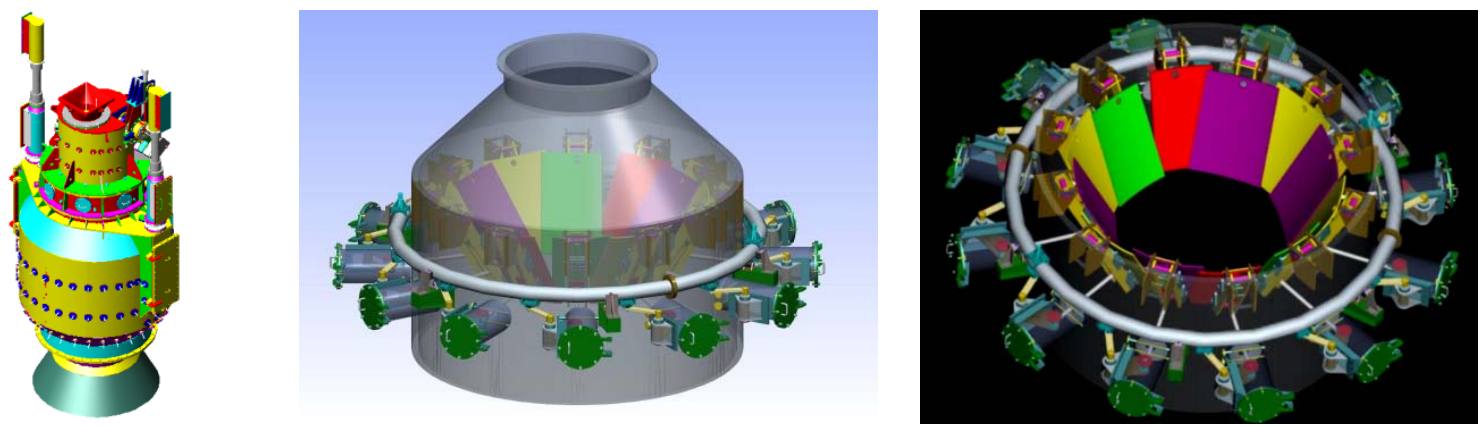

Figura 3. Topo SBPT e distribuidor de placas móveis

O topo consiste de uma tremonha de recebimento de material, uma calha rotativa para distribuição no interior do silo, válvulas de selagem, pressurização e alívio do silo, além de um cone único para descarga no interior do forno.

O sistema confere à VSB excelente vedação do topo do forno o que, por sua vez, permite uma contrapressão de até $0,40 \mathrm{bar}(\mathrm{g})$. O equipamento é, também, muito mais compacto em sua instalação do que os tradicionais sistemas de duplo cone com tremonha pressurizada. A título de exemplo, do flange do topo à tremonha de recebimento do material, o SBPT da VSB possui apenas 5,7 $\mathrm{m}$ de altura.

O silo do topo, com $15 \mathrm{~m}^{3}$ de volume interno, auxilia na flexibilização dos modos de carregamento possíveis para a VSB. A pressurização do silo se dá com o uso de gás semi-limpo proveniente do estágio úmido da lavagem de gás. Novamente, temse um reaproveitamento de energia e gás.

O carregamento do alto-forno da VSB está equipado com um distribuidor de placas móveis. Consistente de um anel acionado hidraulicamente, o equipamento permite, mediante um avanço controlado dos cilindros de acionamento, a variação da angulação das placas defletoras de material no interior do alto-forno.

Com tal dispositivo, a VSB possui maior controle da distribuição de carga do que quando comparado a sistemas tradicionais de placas fixas. O uso de válvulas de retenção no circuito hidráulico do distribuidor garante boa manutenção da posição das placas durante o uso do equipamento e ao longo do tempo, oferecendo boa consistência operacional.

Com um melhor controle da distribuição de carga, a VSB possui ferramentas com as quais ajustar a carga do alto-forno para taxas elevadas de injeção, obter um melhor controle da carga térmica do reator assim como de seu rendimento gasoso. 


\subsection{Geração de Ar Quente}

A VSB possui três sopradores centrífugos de estágio único, sendo um para cada alto-forno e um em stand-by. Sua pressão máxima de trabalho de 1,3 bar(g) confere à operação flexibilidade em termos de escoamento gasoso e também permite uma taxa de sopro de até $50.000 \mathrm{Nm}^{3} / \mathrm{h}$.

$\mathrm{O}$ uso de três regeneradores de câmara de combustão interna para cada alto-forno permite à VSB o uso de temperaturas de sopro de até $1.100^{\circ} \mathrm{C}$, muito superiores à média de $850^{\circ} \mathrm{C}$ comumente usada em altos-fornos a carvão vegetal operando com glendons (ou até mesmo com regeneradores). $O$ uso de temperaturas mais elevadas de sopro reduz o consumo de carvão, desde que a temperatura de chama seja devidamente controlada de modo a não comprometer a descida de carga e a qualidade do gusa. A disponibilidade de até $1.100{ }^{\circ} \mathrm{C}$ de temperatura de sopro, novamente, permite à VSB o uso de coque metalúrgico.

O design inclui uma câmara de mistura para controle da temperatura de sopro mediante diluição do sopro quente com um by-pass de ar frio dos sopradores.

Ainda no tocante ao condicionamento do sopro, a VSB possui a possibilidade de usar até $6 \%$ de enriquecimento de oxigênio no forno $\left(\sim 3.000 \mathrm{Nm}^{3} / \mathrm{h}\right)$, permitindo controle da queima do carvão injetado e flexibilidade para acerto do volume de sopro, rendimento gasoso e permeabilidade do reator.

\subsection{Casa de Corrida}

A casa de corrida do alto-forno 2 da VSB está equipada com uma máquina combinada (canhão e perfuratriz). A máquina de tamponar (canhão) possui liberdade de inclinação para adaptação ao furo de corrida e o sistema hidráulico possui válvulas proporcionais que permitem o controle da velocidade, posição e pressão dos movimentos de desaceleração e compressão da máquina.

O mesmo se aplica à máquina perfuratriz, equipada também com resfriamento da broca com nitrogênio pressurizado e válvula de retenção para proteção do mandril contra retorno de gusa líquido.

Os canais de gusa e escória são resfriados por ar ambiente em convecção natural, uma vez que o fundo dos canais tem contato com ar atmosférico. O canal de gusa possui termopares para monitoramento do desgaste de seu revestimento refratário. $\mathrm{O}$ design em $\mathrm{Y}$ do canal de gusa permite a alternância de uma dada corrida em mais de uma panela sem necessidade de interrupção.

O canal principal contempla facilidades para limpeza com saída lateral para materiais de descarte e baia de resíduos dedicada, o que facilita as operações de manutenção realizadas pelos operadores.

\subsection{Granulação de Escória}

A VSB possui dois tanques de granulação com leito filtrante para atendimento à produção de escória dos dois altos-fornos. O uso de uma claim-shell dispensa o uso de retroescavadeiras e equipamentos semelhantes, basicamente eliminando 0 contato entre operadores e escória. A escória granulada é descarregada pelo equipamento em uma tremonha cuja descarga é transportada por correia transportadora para silos de desaguamento e expedição do material para cimenteiras. 
A água de granulação é integralmente recirculada, economizando recursos e evitando a contaminação do meio ambiente.

\subsection{Sistema de Lavagem de Gases}

O alto-forno da VSB está equipado com um coletor de pó de eficiência de captura estimada em $45-65 \%$, reduzindo a carga de pó do gás de 30 para $15 \mathrm{~g} / \mathrm{Nm}^{3}$. A descarga do balão de pó é com pug mill, isso é, uma rosca helicoidal com adição de água. Esse equipamento reduz drasticamente a dispersão de pó durante a descarga do coletor de pó, resultando em ganhos ambientais.

O estágio a úmido é um diferencial, destacando-se o scrubber com elemento anular. Esse equipamento é responsável não só pela redução da carga de pó de $15 \mathrm{~g} / \mathrm{Nm}^{3}$ para menos de $5 \mathrm{mg} / \mathrm{Nm}^{3}$, mas também pelo controle da pressão de topo do forno mediante o posicionamento do elemento anular. A pressão de saída do lavador pode ser controlada de $600-700 \mathrm{mmCa}$ até a pressão do topo. O avanço hidráulico do cilindro do elemento oferece um controle fino e confiável da pressão, ao mesmo tempo em que o tratamento de superfície empregado no equipamento oferece tempos de campanha longos.

A câmara superior do scrubber fornece gás semi-limpo para equalização do silo do topo, conforme previamente mencionado. A mesma linha possui uma válvula bleeder de gás semi-limpo que é a primeira a se abrir no caso de uma sobrepressão do topo do alto-forno como no caso de um arriamento de carga, oferecendo, portanto, vantagens ambientais à operação.

A umidade residual do gás de alto-forno é retirada em um separador de névoa (demister) e o gás é queimado em duas tochas, cujo controle é automaticamente realizado por duas válvulas de controle de pressão. Toda a água da lavagem de gás, tanto do scrubber como do demister é recirculada e tratada, reduzindo o consumo de água da unidade e evitando a contaminação do meio ambiente.

\subsection{Injeção de Carvão Pulverizado}

O alto-forno da VSB possui um sistema de moagem, secagem e injeção de carvão pulverizado projetado pela Küttner do Brasil. O sistema permite o aproveitamento de $100 \%$ da moinha gerada no peneiramento de carvão da usina e utiliza gás de altoforno na secagem do carvão, gerando, portanto, dois reaproveitamentos e resultando em redução do consumo de carvão vegetal pelo topo do alto-forno.

O sistema é equipado com dois vasos de operação alternada que garantem injeção contínua e estável no reator, sendo usadas lanças de injeção duplas. Com dupla lança, o sistema possui flexibilidade para maiores taxas de injeção ao mesmo passo em que se mantêm velocidades mais baixas nas lanças, reduzindo o desgaste das mesmas.

O sistema possui capacidade para uma razão específica de injeção de até 165 $\mathrm{kg} / \mathrm{tgusa}(\sim 6.700 \mathrm{~kg} / \mathrm{h})$ sendo a capacidade de enriquecimento de oxigênio do sopro de até $6 \%$, conforme previamente apresentado. 


\subsection{Manuseio de Gusa}

Conforme previamente mencionado, o canal de gusa em $Y$ utilizado no projeto permite o enchimento de mais de uma panela por corrida sem necessidade de interrupção para troca da panela e, acima de tudo, sem nenhum tipo de respingo ou perda de material durante a troca.

O galpão de manuseio de gusa é equipado com uma ponte rolante para transporte das panelas. Há um carro de transferência a ser guinchado para a aciaria, sendo o carro pesado vazio e com a panela, antes que essa saia do galpão. O sistema de pesagem envia automaticamente os pesos obtidos para a sala de controle do altoforno. O caminho até a aciaria é da ordem de $100 \mathrm{~m}$, logo todo o transporte se dá rapidamente e com baixas perdas de temperatura. Novamente, o design permite, portanto, a economia de energia.

Outra opção de destinação da produção de gusa é a máquina de lingotar gusa (Pig Casting Machine). Equipada com basculador hidráulico de panelas, a máquina permite um controle preciso da vazão de lingotamento nos dois veios com que está equipada. Os veios podem ser operados simultânea ou alternadamente, conforme demanda. Originalmente, a máquina foi concebida para operar apenas durante paradas da aciaria ou durante períodos de qualidade inadequada de gusa (contanto que a temperatura e o teor de silício estivessem dentro de limites pré-definidos). Com tal máquina, a VSB pode manter a produção dos fornos em ritmo e qualidade adequados, sem comprometimento da qualidade do gusa.

Desde seu início de operação em julho de 2014, a máquina tem, entretanto, operado quase que continuamente devido a uma menor demanda de gusa líquido pela aciaria. Com tal desempenho, mesmo em períodos de baixa demanda o alto-forno pode manter sua operação, sem necessidade de reduzir a marcha ou parar.

Enfim, mesmo durante paradas da máquina de lingotar gusa, a VSB dispõe também de uma baia de emergência. Com todas essas opções, tem-se, portanto, capacidade de blindar a operação do forno contra paradas por demanda ou paradas da aciaria.

\subsection{Controle Ambiental}

A VSB dispõe de desempoeiramento em todos os pontos de transferência de material assim como nos peneiramentos, topo do forno e casa de corrida, esses últimos com separador de fagulhas para proteção das mangas dos filtros. Os sistemas atendem bem a demanda e, mesmo após sete meses de operação, a usina continua com limpeza marcante, mesmo na casa de corrida.

Um destaque é a coifa móvel de despoeiramento do furo de corrida. Com seu acionamento hidráulico, a coifa fica em posição de repouso quando fora de uso e é movimentada sobre o furo de corrida já durante a operação de perfuração do forno. Dessa forma, a coifa contribui em muito para a redução ou até mesmo eliminação das tradicionais "névoas" negras ou vermelhas observadas comumente durante a abertura de furos de corrida em altos-fornos. A segurança dos operadores também é significativamente incrementada.

\section{RESULTADOS OPERACIONAIS E CONCLUSÃO}

Os principais resultados e comentários acerca do start-up são o objeto do trabalho "O início de operação do alto-forno 2 da VSB", também apresentado no presente seminário. 
Embora ainda se classifique, devido ao seu nível de produção, como um "mini altoforno", o alto-forno 2 da VSB, cuja operação teve início em julho de 2014, não perde em nada para altos-fornos maiores em termos de equipamentos disponíveis e instrumentação instalada. A VSB possui em mãos tecnologias avançadas para uma operação estável e segura do alto-forno, produzindo gusa de qualidade de maneira sustentável e ambientalmente correta. 